\title{
Glass Transition Temperature of Homogeneous Blends and Copolymers
}

\author{
Shoji ICHIHARA ${ }^{\dagger}$ \\ Tsukuba Research Center, Mitsubishi Chemical Co., Ami, Ibaraki, 300-0397, Japan
}

(Received February 8, 2000; Accepted June 5, 2000)

\begin{abstract}
The volume change of mixing is the difference of the volume of a blend and that of ideal blend, calculated with additive equation. The glassy state is non-equilibrium state and thus has the excess volume against equilibrium state. If the glass transition temperature, $T_{\mathrm{g}}$, of a blend, $T_{\mathrm{gB}}$, is not equal to $T_{\mathrm{g}}$ calculated with Gordon-Taylor equation, $T_{\mathrm{gAv}}$, the volume change of mixing changes discontinuously at $T_{\mathrm{gB}}$ because excess volume vitrified at $T_{\mathrm{gB}}$ and $T_{\mathrm{gAv}}$ is different. The situation is similar for enthalpy and entropy. Assuming that volume change, enthalpy or entropy of mixing at $T_{\mathrm{gB}}$ is proportional to the product of mole fractions of component polymers, equations to express the composition dependence of $T_{\mathrm{gB}}$ are derived. The obtained equations reproduced observed $T_{\mathrm{g}}$ of blends well. Using $T_{\mathrm{gB}}$ thus obtained, $T_{\mathrm{g}}$ of alternating copolymer, and, probability of the presence of hetero sequence in copolymer, the equations to express $T_{\mathrm{g}}$ of copolymers are derived.

KEY WORDS Glass Transition Temperature / Homogeneous Blend / Copolymer /
\end{abstract}

The relationship between glass transition temperatures of homogeneous blends and constituent polymers, and, that of copolymers and homopolymers are still of interest. Assuming that volume change of mixing of ideal blend is zero not only in liquid state but also in the glassy state, Gordon and Taylor derived the equation, below, ${ }^{1}$

$$
\begin{aligned}
& T_{\mathrm{gAv}}=\left(w_{1} \Delta \beta_{1} T_{\mathrm{g} 1}+w_{2} \Delta \beta_{2} T_{\mathrm{g} 2}\right) / \Delta \beta_{\mathrm{m}} \\
& \Delta \beta_{\mathrm{m}}=w_{1} \Delta \beta_{1}+w_{2} \Delta \beta_{2}
\end{aligned}
$$

where $T_{\mathrm{g}}$ is glass transition temperature, $w$, weight fraction of polymer, and, $\Delta \beta$, the difference of the expansion coefficients, $\beta$, between liquid and glassy states at $T_{\mathrm{g}}$. Suffixes 1 and 2 represent constituent polymers 1 and 2 respectively. Suffix Av represents the assumption that the volume of a blend is expressed by additive equation of volumes of constituent polymers. $\Delta \beta_{\mathrm{m}}=w_{1} \Delta \beta_{1}+$ $w_{2} \Delta \beta_{2}$ is weighted average of $\Delta \beta_{i}$ where $\mathrm{i}$ is 1 or 2 . The definition of the expansion coefficient in these equations is $\beta=(\partial v / \partial T)_{\mathrm{p}}$ where $v$ is specific volume and $T$, temperature.

Assuming that the enthalpy of mixing is zero in liquid and glassy states, Wood derived similar equations, ${ }^{2}$

$$
\begin{aligned}
T_{\mathrm{gAh}} & =\left(w_{1} \Delta c_{\mathrm{p} 1} T_{\mathrm{g} 1}+w_{2} \Delta c_{\mathrm{p} 2} T_{\mathrm{g} 2}\right) / \Delta c_{\mathrm{pm}} \\
\Delta c_{\mathrm{pm}} & =w_{1} \Delta c_{\mathrm{p} 1}+w_{2} \Delta c_{\mathrm{p} 2}
\end{aligned}
$$

where $\Delta c_{\mathrm{pi}}$ is specific heat change of constituent polymer $\mathrm{i}$ at $T_{\mathrm{gi}}$, and, suffix $\mathrm{Ah}$ represents the assumption that the enthalpy of mixing is expressed by additive equation.

Assuming that the entropy of mixing of polymers is negligibly small in liquid and glassy states, Cauchman derived the equation, ${ }^{3}$

$$
\ln T_{\mathrm{gAh}}=\left(w_{1} \Delta c_{\mathrm{p} 1} \ln T_{\mathrm{g} 1}+w_{2} \Delta c_{\mathrm{p} 2} \ln T_{\mathrm{g} 2}\right) / \Delta c_{\mathrm{pm}}
$$

Suffix As represents the assumption that the entropy of mixing is expressed by an additive equation.

The glass transition temperature of "non-ideal" blend, $T_{\mathrm{gB}}$, is not well reproduced by these equations and thus Kwei proposed an empirical equation. ${ }^{4}$ His equation is a modified Gordon-Taylor equation in which an empirical constant is included. The meaning of this empirical constant has not been clarified. Taking intermolecular interactions into consideration, Schneider proposed another modified Gordon-Taylor equation in which two parameters are included. ${ }^{5}$ It is questionable that $T_{\mathrm{gB}}$ can be described by thermodynamic considerations as above though the glass transition temperature of materials cannot be described in terms of relaxation. In this paper, the limit of thermodynamic treatments is considered and the semi-empirical relationships of $T_{\mathrm{gB}}$ are discussed.

Composition dependence of $T_{\mathrm{g}}$ of copolymers is different from that of blends. Usually, the glass transition temperature of alternating copolymer, $T_{\mathrm{gAL}}$, and that of random copolymer at equi-molar composition are not equal. This means that the probability of presence of hetero sequence, $p$, affects $T_{\mathrm{g}}$ of copolymers, $T_{\mathrm{gCP}}$. If $p=$ 1 , the copolymer is an alternating copolymer. If $p=0$ and phase separation does not occur, the system becomes a homogeneous blend. Hirooka and Kato ${ }^{6}$ explained $T_{\mathrm{g}}$ of copolymers of equi-molar composition by $T_{\mathrm{gAL}}, p$ calculated from monomer reactivity ratios, and, mean values of $T_{\mathrm{g} 1}$ and $T_{\mathrm{g} 2}$. The use of mean $T_{\mathrm{g}}$ is not adequate to describe $T_{\mathrm{gB}}$. They did not discuss the composition dependence of $T_{\mathrm{g}}$ of copolymers. In this paper, the composition dependence of $T_{\mathrm{g}}$ of copolymers is discussed.

\section{ASSUMPTIONS AND PROCEDURE}

\section{$T_{g}$ of Homogeneous Blends, $T_{g B}$}

Though glass transition is a relaxation phenomenon, molecular dynamics studies have not been successful in

${ }^{\dagger}$ Present address: Department of Organic and Polymeric Materials Chemistry, Faculty of Technology, Tokyo University of Agriculture and Technology, Koganei, Tokyo, 184-8588 Japan. 
explicitly expressing $T_{\mathrm{g}}$ for various materials. Here, we try to derive semi-empirical expressions for $T_{\mathrm{g}}$ considering changes in volume, enthalpy or entropy of constituent polymers and blends at $T_{\mathrm{g}} . T_{\mathrm{g}}$ discussed in this paper is for certain definite conditions of measurements. An example of such conditions is the same and constant rate cooling. For $T_{\mathrm{g}}$ obtained by heating experiments, at least it is necessary that $\lambda$-shaped peak of specific heat or expansion coefficient in glass transition region is negligible.

In liquid state, the molar volume of a non-ideal blend, $V_{\mathrm{BL}}(T)$, is expressed by,

$$
V_{\mathrm{BL}}(T)=x_{1} V_{1 \mathrm{~L}}(T)+x_{2} V_{2 \mathrm{~L}}(T)+\Delta V_{\mathrm{L}}(T)
$$

where $V_{\mathrm{iL}}(T)$ and $x_{\mathrm{i}}$ are molar volume and mole fraction of component i respectively. Suffix B represents the value of non-ideal blend, and $L$, the value in liquid state. $\Delta V_{\mathrm{L}}(T)$ is the molar volume change of mixing in liquid state. The specific volume of a non-ideal blend is expressed by,

$$
v_{\mathrm{BL}}(T)=v_{\mathrm{AL}}(T)+\Delta v_{\mathrm{L}}(T)
$$

where

$$
v_{\mathrm{AL}}(T) \equiv w_{1} v_{1 \mathrm{~L}}(T)+w_{2} v_{2 \mathrm{~L}}(T)
$$

and $\Delta v_{\mathrm{L}}(T)=\Delta V_{\mathrm{L}}(T) /\left(x_{1} M_{1}+x_{2} M_{2}\right) . M_{1}$ and $M_{2}$ are the molecular weight of repeating units of polymer 1 and 2 respectively. Usually, it is assumed that the specific volume of a blend in glassy state is expressed by,

$$
v_{\mathrm{BG}}(T)=v_{\mathrm{AG}}(T)+\Delta \mathrm{v}_{\mathrm{G}}(T)
$$

where

$$
v_{\mathrm{AG}}(T) \equiv w_{1} v_{1 \mathrm{G}}(T)+w_{2} v_{2 \mathrm{G}}(T)
$$

Suffix $\mathrm{G}$ represents the value in glassy state.

$v_{\mathrm{iL}}(T)$ and $v_{\mathrm{iG}}(T)$ are expressed as follows;

$$
\begin{aligned}
& v_{\mathrm{iL}}(T)=v_{\mathrm{i}}\left(T_{\mathrm{gi}}\right)+\beta_{\mathrm{iL}}\left(T-T_{\mathrm{gi}}\right) \\
& v_{\mathrm{iG}}(T)=v_{\mathrm{i}}\left(T_{\mathrm{gi}}\right)+\beta_{\mathrm{iG}}\left(T-T_{\mathrm{gi}}\right)
\end{aligned}
$$

If $\Delta v_{L}(T)=\Delta v_{G}(T)=0$, the temperature of intersection of $v_{\mathrm{AL}}(T)$ and $v_{\mathrm{AG}}(T)$ is $T_{\mathrm{g}}$ for an ideal blends, $T_{\mathrm{gAv}}$, and, is given by eq 1 . Excess volume by vitrification of this blend at $T$ is expressed by,

$$
v_{\mathrm{AG}}(T)-v_{\mathrm{AL}}(T)=\Delta \beta_{\mathrm{m}}\left(T_{\mathrm{gAv}}-T\right)
$$

This excess volume by vitrification is equal to the weighted average of excess volume of polymers 1 and 2 vitrified at $T_{\mathrm{g} 1}$ and $T_{\mathrm{g} 2}$ respectively.

When $\Delta v_{\mathrm{L}}$ and $\Delta v_{\mathrm{G}}$ are not zero, $v_{\mathrm{BL}}(T)=v_{\mathrm{AL}}(T)+$ $\Delta v_{\mathrm{L}}(T)$ becomes equal to $v_{\mathrm{BG}}(T)=v_{\mathrm{AG}}(T)+\Delta v_{\mathrm{G}}(T)$ at $T_{\mathrm{gB}}$. Using $T_{\mathrm{gAv}}$, this relationship is expressed by,

$$
\begin{aligned}
& v_{\mathrm{AL}}\left(T_{\mathrm{gAv}}\right)+\left(w_{1} \beta_{1 \mathrm{~L}}+w_{2} \beta_{2 \mathrm{~L}}\right)\left(T_{\mathrm{gB}}-T_{\mathrm{gAv}}\right)+\Delta v_{\mathrm{L}}\left(T_{\mathrm{gB}}\right) \\
= & v_{\mathrm{AG}}\left(T_{\mathrm{gAv}}\right)+\left(w_{1} \beta_{1 \mathrm{G}}+w_{2} \beta_{2 \mathrm{G}}\right)\left(T_{\mathrm{gB}}-T_{\mathrm{gAv}}\right)+\Delta v_{\mathrm{G}}\left(T_{\mathrm{gB}}\right)
\end{aligned}
$$

As $v_{\mathrm{AL}}\left(T_{\mathrm{gAv}}\right)=v_{\mathrm{AG}}\left(T_{\mathrm{gAv}}\right)$, the above equation is rewritten as follows;

$$
\begin{aligned}
\Delta \beta_{\mathrm{m}}\left(T_{\mathrm{gAv}}-T_{\mathrm{gB}}\right) & =\Delta v_{\mathrm{L}}\left(T_{\mathrm{gB}}\right)-\Delta v_{\mathrm{G}}\left(T_{\mathrm{gB}}\right) \\
& =v_{\mathrm{AG}}\left(T_{\mathrm{gB}}\right)-v_{\mathrm{AL}}\left(T_{\mathrm{gB}}\right)
\end{aligned}
$$

Equation 10 means that, if $T_{\mathrm{gAv}} \neq T_{\mathrm{gB}}$, volume change of mixing changes discontinuously at $T_{\mathrm{gB}}$ though the volume of blend is continuous. This is due to the definition of $v_{\mathrm{AG}}(T)$. Polymers 1 and 2 in non-ideal blend vitrify at $T_{\mathrm{gB}}$ and the excess volume of blend by vitrification is zero at $T_{\mathrm{gB}}$. An ideal blend vitrifies at $T_{\mathrm{gAv}}$ and excess volume by vitrification at $T_{\mathrm{gB}}$ is $\Delta v_{\mathrm{L}}\left(T_{\mathrm{gB}}\right)-\Delta v_{\mathrm{G}}\left(T_{\mathrm{gB}}\right)$. This value is determined by $T_{\mathrm{gB}}$, and so $T_{\mathrm{gB}}$ cannot be estimated by Eq 10 even if $\Delta v_{\mathrm{L}}(T)$ is calculated considering the intermolecular interactions. That is, $T_{\mathrm{gB}}$ is determined not only by intermolecular interactions but also the mechanism of glass transition itself. However, if the composition dependence of $\Delta v_{\mathrm{L}}\left(T_{\mathrm{gB}}\right)-\Delta v_{\mathrm{G}}\left(T_{\mathrm{gB}}\right)$ is expressed with an empirical equation, an empirical expression to relate $T_{\mathrm{gAv}}$ with $T_{\mathrm{gB}}$ is obtained.

The composition dependence of $\Delta v(T)$ can be approximately expressed by the product of mole fractions, weight fractions or volume fractions of component polymers. In this paper, it is assumed that $\Delta v(T)$ is proportional to $x_{1} x_{2}$ and its temperature change is small. Namely, $\Delta v_{\mathrm{L}}\left(T_{\mathrm{gB}}\right)-\Delta v_{\mathrm{G}}\left(T_{\mathrm{gB}}\right)$ is assumed to be expressed by,

$$
\Delta v_{\mathrm{L}}\left(T_{\mathrm{gB}}\right)-\Delta v_{\mathrm{G}}\left(T_{\mathrm{gB}}\right)=4 x_{1} x_{2} \delta_{\mathrm{v}}
$$

where $\delta_{\mathrm{v}}$ is the value of $\Delta v_{\mathrm{L}}\left(T_{\mathrm{gB}}\right)-\Delta v_{\mathrm{G}}\left(T_{\mathrm{gB}}\right)$ at equimolar composition. Using these assumptions, the relationship between $T_{\mathrm{gB}}$ and $T_{\mathrm{gAv}}$ is expressed by,

$$
T_{\mathrm{gB}}=T_{\mathrm{gAv}}-4 x_{1} x_{2} \delta_{\mathrm{v}} / \Delta \beta_{\mathrm{m}}
$$

If $\Delta v(T)$ is proportional to $w_{1} w_{2}$, eq 12 becomes Kwei's equation. ${ }^{4}$

Similar procedure can be applied to the enthalpy and entropy of mixing. The enthalpy of mixing per unit mass is expressed by $\Delta h=h_{\mathrm{B}}-\left(w_{1} h_{1}+w_{2} h_{2}\right)$ where $h$ is enthalpy per unit mass. If the similar procedure is applied to enthalpy and if the temperature dependence of specific heat of polymer $\mathrm{i}$ in glassy state is approximately equal to that in liquid state, $\Delta \beta, \Delta v$, and suffix $v$ in eq 10 are replaced with $\Delta c_{\mathrm{p}}, \Delta h$, and suffix $h$ respectively. The result is,

$$
\Delta c_{\mathrm{pm}}\left(T_{\mathrm{gAh}}-T_{\mathrm{gB}}\right)=\Delta h_{\mathrm{L}}\left(T_{\mathrm{gB}}\right)-\Delta h_{\mathrm{G}}\left(T_{\mathrm{gB}}\right)
$$

The relationship between $T_{\mathrm{gB}}$ and $T_{\mathrm{gAh}}$ is,

$$
T_{\mathrm{gB}}=T_{\mathrm{gAh}}-4 x_{1} x_{2} \delta_{\mathrm{h}} / \Delta c_{\mathrm{pm}}
$$

where $\delta_{\mathrm{h}}$ is $\Delta h_{\mathrm{L}}\left(T_{\mathrm{gB}}\right)-\Delta h_{\mathrm{G}}\left(T_{\mathrm{gB}}\right)$ at equi-molar composition.

The entropy of mixing per unit mass is expressed by $\Delta s=s_{\mathrm{B}}-\left(w_{1} s_{1}+w_{2} s_{2}\right)$ where $s$ is entropy per unit mass. Similarly, $T_{\mathrm{gB}}$ and $T_{\mathrm{gAh}}$ in eq 13 are replaced by $\ln T_{\mathrm{gB}}$ and $\ln T_{\mathrm{gAs}}$ respectively because $(\partial s / \partial T)_{\mathrm{p}}=c_{\mathrm{p}} / T$. So that,

$$
\begin{aligned}
& \Delta c_{\mathrm{pm}}\left(\ln T_{\mathrm{gAs}}-\ln T_{\mathrm{gB}}\right)=\Delta s_{\mathrm{L}}\left(T_{\mathrm{gB}}\right)-\Delta s_{\mathrm{G}}\left(T_{\mathrm{gB}}\right) \\
& \ln T_{\mathrm{gB}}=\ln T_{\mathrm{gAs}}-4 x_{1} x_{2} \delta_{\mathrm{S}} / \Delta c_{\mathrm{pm}}
\end{aligned}
$$

where $\delta_{\mathrm{s}}$ is $\Delta s_{\mathrm{L}}\left(T_{\mathrm{gB}}\right)-\Delta s_{\mathrm{G}}\left(T_{\mathrm{gB}}\right)$ at equi-molar composition.

\section{$T_{g}$ of Copolymers, $T_{g C P}$}

The glass transition temperature of alternating copolymer, $T_{\mathrm{gAL}}$ is different from that of random copolymer at equi-molar composition. ${ }^{6}$ That is, $T_{\mathrm{g}}$ of a copolymer composed of two monomeric units, $T_{\mathrm{gCP}}$, changes with the probability of presence of hetero sequence, $p$. If $p=1$, 


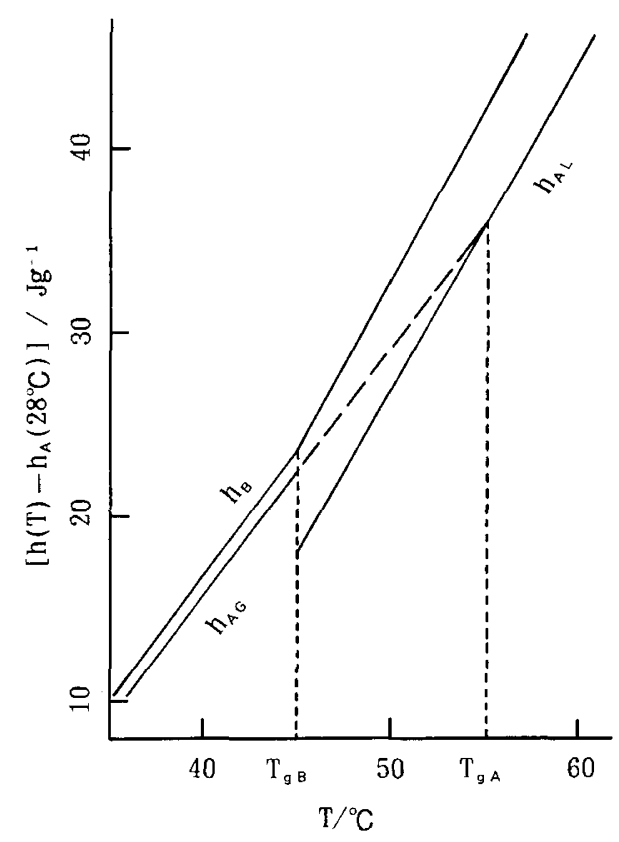

Figure 1. Enthalpy of blend, $h_{\mathrm{B}}$, and $h_{\mathrm{A}}=w_{1} h_{1}+w_{2} h_{2}$ of PMMA/ PVAc blend at $w_{\mathrm{PMMA}}=0.4 . h_{\mathrm{A}}$ at $28^{\circ} \mathrm{C}$ is assumed to be $0 . T_{\mathrm{gB}}$ is glass transition temperature of blend at this composition, and $T_{\mathrm{gA}}$, that calculated by Wood's equation.

the copolymer is alternating and $T_{\mathrm{gCP}}$ is equal to $T_{\mathrm{gAL}}$. If $p=0$, and phase separation does not occur, the system becomes a homogeneous blend and $T_{\mathrm{gCP}}$ is equal to $T_{\mathrm{gB}}$. Namely,

$$
T_{\mathrm{gCP}}-T_{\mathrm{gB} 50}=T_{\mathrm{gAL}}-T_{\mathrm{gB} 50} \text { if } p=1
$$

and

$$
T_{\mathrm{gCP}}-T_{\mathrm{gB}}=0 \text { if } p=0
$$

where $T_{\mathrm{gB} 50}$ is $T_{\mathrm{gB}}$ at equi-molar composition. When $p$ increases, the difference between $T_{\mathrm{gCP}}$ and $T_{\mathrm{gB}}$ becomes large. If $T_{\mathrm{gCP}}-T_{\mathrm{gB}}$ is proportional to $p$ and the proportional coefficient is $T_{\mathrm{gAL}}-T_{\mathrm{gB} 50}$, then,

$$
T_{\mathrm{gCP}}=T_{\mathrm{gB}}+p\left(T_{\mathrm{gAL}}-T_{\mathrm{gB} 50}\right)
$$

$T_{\mathrm{gB}}$ is given by eqs 12,14 , or 16 .

The probability of presence of hetero diad is $2 x_{1} x_{2}$ for random copolymer composed of two monomeric units, $p$ of hetero triad is $3 x_{1} x_{2}$. If glass transition temperature of a random copolymer composed of two monomeric units, $T_{\mathrm{gRD}}$, is determined by $p$ of heterodiad and $T_{\mathrm{gB}}$ is expressed by eq $12, T_{\mathrm{gRD}}$ is,

$$
\begin{aligned}
& T_{\mathrm{gRD}}=T_{\mathrm{gB}}+2 x_{1} x_{2}\left(T_{\mathrm{gAL}}-T_{\mathrm{gB}} 50\right) \\
& =T_{\mathrm{gAv}}+2 x_{1} x_{2}\left(T_{\mathrm{gAL}}-T_{\mathrm{gAv} 50}+\delta_{\mathrm{v}} / \Delta \beta_{\mathrm{m} 50}\right)-4 x_{1} x_{2} \delta_{\mathrm{v}} / \Delta \beta_{\mathrm{m}}
\end{aligned}
$$

$T_{\mathrm{gAv} 50}$ and $\Delta \beta_{\mathrm{m} 50}$ are $T_{\mathrm{gAv}}$ and $\Delta \beta_{\mathrm{m}}$ at equi-molar composition respectively. This equation is rewritten as follows;

$$
T_{\mathrm{gRD}}=T_{\mathrm{gAv}}+g x_{1} x_{2}\left(T_{\mathrm{gAL}}-T_{\mathrm{gAv} 50}\right)
$$

where,

$$
(g-2)\left(T_{\mathrm{gAL}}-T_{\mathrm{gAv} 50}\right)=\left(2 \delta_{\mathrm{v}} / \Delta \beta_{\mathrm{m} 50}\right)\left(1-2 \Delta \beta_{\mathrm{m} 50} / \Delta \beta_{\mathrm{m}}\right)
$$

If $\Delta \beta_{1}$ is similar to $\Delta \beta_{2}, \Delta \beta_{\mathrm{m}}$ and therefore, $g$ become almost constant.

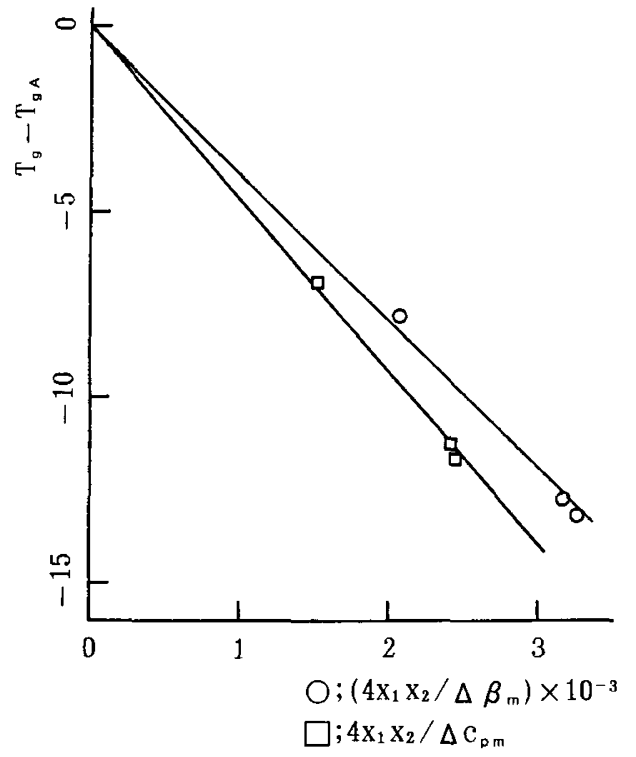

Figure 2. Plots of $T_{g B}-T_{g A v} v s .4 x_{1} x_{2} / \Delta \beta_{\mathrm{m}} \times 10^{-3}(\bigcirc)$ and plot of $T_{\mathrm{gB}}-T_{\mathrm{gAh}}$ vs. $4 x_{1} x_{2} / \Delta c_{\mathrm{pm}}(\square)$ of PMMA/PVAc homogeneous blends.

\section{RESULTS AND DISCUSSION}

\section{Homogeneous Blends}

Though poly(methyl methacrylate) (PMMA) and poly(vinyl acetate) (PVAc) are not mutually soluble, homogeneous blends can be obtained by freeze-drying method. For this blend system, the enthalpy of mixing at $28^{\circ} \mathrm{C}$, composition dependence of $T_{\mathrm{g}}$ and temperature dependence of specific heat are reported. ${ }^{7}$ The specific heat measured with differential scanning calorimeter (DSC) ${ }^{7}$ did not show $\lambda$-shaped peak in glass transition region and the phase separation was not observed within the time of DSC measurements. The applicability of eqs 12 , 14 , and 16 was thus examined for this blend system. At $w_{\text {PMMA }}=0.4$, the enthalpy of mixing at $28^{\circ} \mathrm{C}$ is about $1 \mathrm{~J}$ $\mathrm{g}^{-1}$, and, $T_{\mathrm{g}}$ interpolated to this composition is $45.3^{\circ} \mathrm{C}$. $T_{\text {gPMMA }}$ is $105^{\circ} \mathrm{C}$ and $T_{\text {gPVAc }}$ is $35^{\circ} \mathrm{C} . \Delta \beta$ and $\Delta c_{\mathrm{p}}$ of PMMA are $2.45 \times 10^{-4} \mathrm{~cm}^{3} \mathrm{gK}^{-18}$ and $0.31 \mathrm{~J} \mathrm{gK}^{-19} . \Delta \beta$ and $\Delta c_{\mathrm{p}}$ of PVAc are $3.64 \times 10^{-4} \mathrm{~cm}^{3} \mathrm{gK}^{-110}$ and $0.503 \mathrm{~J} \mathrm{gK}^{-111}$ respectively. From these data, $T_{\text {gAh }}$ at $w_{\text {PMMA }}=0.4$ is calculated as $55.4^{\circ} \mathrm{C}$.

Using these data and assuming $h_{\mathrm{AG}}=w_{1} h_{1}+w_{2} h_{2}$ at $28^{\circ} \mathrm{C}$ is $0, h_{\mathrm{B}}(T)$ and $h_{\mathrm{A}}(T)$ were calculated for $w_{\mathrm{PMMA}}=$ 0.4 blend. The results are shown in Figure $1 . h_{\mathrm{BG}}$ is equal to $h_{\mathrm{BL}}$ at $T_{\mathrm{gB}}$. The ideal blend vitrifies at $T_{\mathrm{gAh}}$, and the value of $h_{\mathrm{AL}}$ extrapolated from $T_{\mathrm{gAh}}$ to $T_{\mathrm{gB}}$ is thus not equal to $h_{\mathrm{AG}}$ at $T_{\mathrm{gB}}$. From Figure $1, \delta_{\mathrm{h}}$ is about $5 \mathrm{~J} \mathrm{~g}^{-1}$. This discontinuity is due to the definition of $h_{\mathrm{AG}}$. As PMMA and PVAc in blend vitrify at $T_{\mathrm{gB}}$, the value of enthalpy of mixing, $\Delta h_{\mathrm{G}}(T)=h_{\mathrm{BG}}(T)-h_{\mathrm{AG}}(T)$, and, the enthalpy of ideal blend in glassy state, $h_{\mathrm{AG}}(T)$, should be corrected using $h_{\mathrm{AL}}\left(T_{\mathrm{gB}}\right)$ to adjust for the difference of the excess enthalpy of vitrification.

If the volume change and enthalpy of mixing are approximately proportional to $x_{1} x_{2}$ and the temperature change is small, from eqs 12 and $14, T_{\mathrm{gB}}-T_{\mathrm{gAv}}$ and $T_{\mathrm{gB}}-$ $T_{\mathrm{gAh}}$ are proportional to $4 x_{1} x_{2} \delta_{\mathrm{v}} / \Delta \beta_{\mathrm{m}}$ and $4 x_{1} x_{2} \delta_{\mathrm{h}} / \Delta c_{\mathrm{pm}}$ 


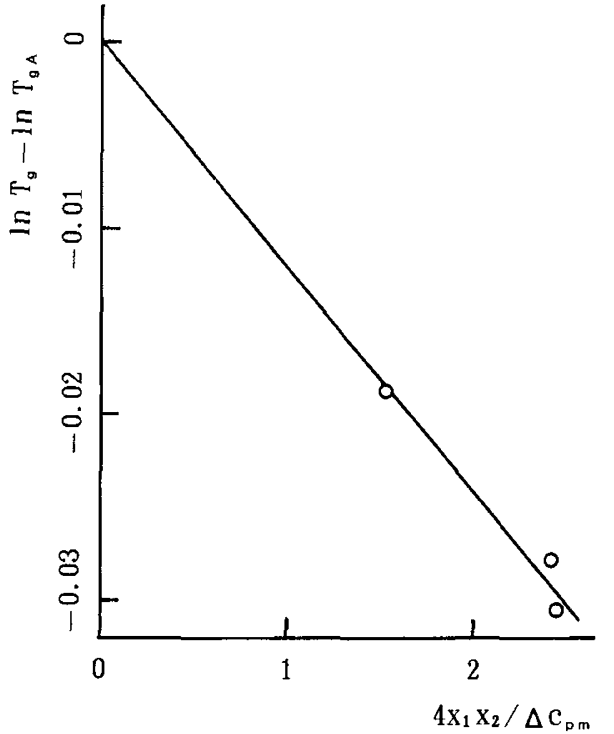

Figure 3. Plots of $\ln \left(T_{\mathrm{gB}} / T_{\mathrm{gAs}}\right)$ vs. $4 x_{1} x_{2} / \Delta c_{\mathrm{pm}}$ of PMMA/PVAc homogeneous blends.

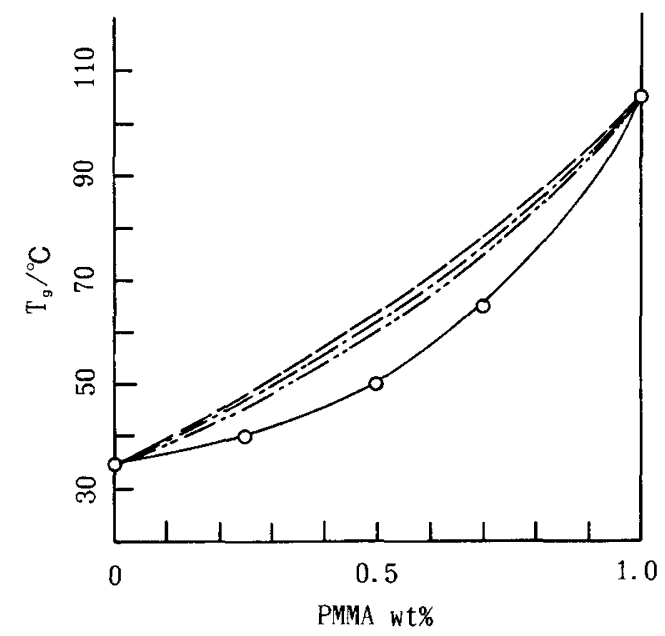

Figure 4. Plots of $T_{\mathrm{g}}$ of homogeneous blends of PMMA/PVAc against compositions. $\bigcirc$; observed values. Solid line; calculated curve using eqs 12,14 , and 16 . Broken line; calculated curve using Gordon-Taylor equation. Dotted broken line; calculated with Wood's equation. Double dotted broken line; calculated with Cauchman's equation.

respectively. Figure 2 shows plot of $T_{\mathrm{gB}}-T_{\mathrm{gAv}}$ against 4 $x_{1} x_{2} \delta_{\mathrm{v}} / \Delta \beta_{\mathrm{m}}$ and, $T_{\mathrm{gB}}-T_{\mathrm{gAh}}$ against $4 x_{1} x_{2} \delta_{\mathrm{h}} / \Delta c_{\mathrm{pm}}$. Figure 2 shows proportional relationships between these quantities for this blend system. Mean $\delta_{\mathrm{v}}$ and $\delta_{\mathrm{h}}$ are $4.0 \times 10^{-3} \mathrm{~cm}^{3} \mathrm{~g}^{-1}$ and $4.7 \mathrm{~J} \mathrm{~g}^{-1}$, and, the difference between maximum and minimum $\delta_{\mathrm{v}}$ and $\delta_{\mathrm{h}}$ are $9 \%$ and $5 \%$ respectively. If $x_{1} x_{2}$ in eqs 12 and 14 are replaced by $w_{1} w_{2}$, the difference between maximum and minimum $\delta_{\mathrm{v}}$ and $\delta_{\mathrm{h}}$ become $22 \%$ and $17 \%$ respectively. This is the reason why the product of mole fractions is used in this paper. The difference between $\delta_{\mathrm{h}}$ obtained from Figures 1 and 2 is within experimental error.

If the entropy of mixing is approximately proportional

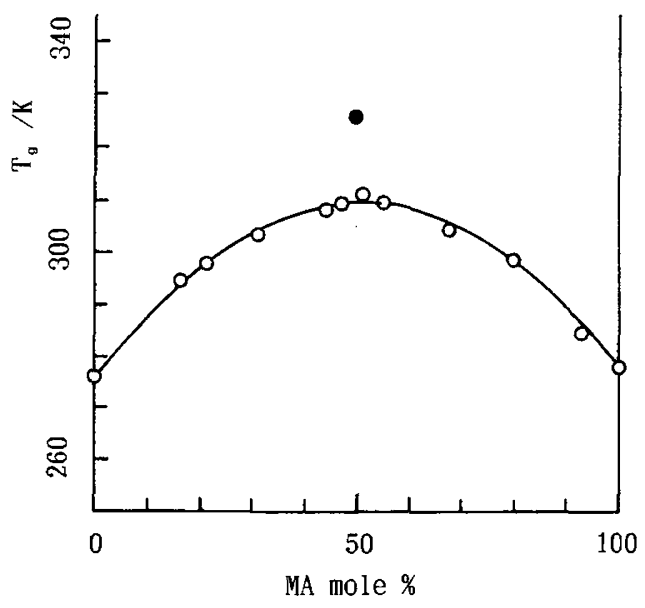

Figure 5. $T_{\mathrm{g}}$ of $\mathrm{p}(\mathrm{MA}-\mathrm{co}-\mathrm{VDC}) . \bigcirc$; random copolymers. $\mathrm{O}$; alternating copolymer. Solid line; calculated with eq $11 . \mathrm{g}$ is assumed to be constant, and, is 2.64 .

to $x_{1} x_{2}$ and its temperature change is small, from eq 16 , $\ln T_{\mathrm{gB}}-\ln T_{\mathrm{gAs}}$ is proportional to $4 x_{1} x_{2} / \Delta c_{\mathrm{pm}}$. Figure 3 shows that $\ln T_{\mathrm{gB}}-\ln T_{\mathrm{gAs}}$ is proportional to $4 x_{1} x_{2} / \Delta c_{\mathrm{pm}}$. Mean $\delta_{\mathrm{s}}$ is $1.2 \times 10^{-2} \mathrm{~J} \mathrm{gK}^{-1}$, and, the difference between maximum and minimum $\delta_{\mathrm{s}}$ is $8 \%$. Though it is thought that the entropy of mixing of polymer blend in liquid state is small, $\delta_{\mathrm{s}}$, and therefore, $\Delta S_{\mathrm{G}}\left(T_{\mathrm{gB}}\right)$ are not so small. This suggests that not only the interaction between constituent polymers but also the mechanism of vitrification determine the glass transition temperature of homogeneous blends.

Figure 4 shows calculated curves of $T_{\mathrm{gB}}, T_{\mathrm{gAv}}, T_{\mathrm{gAh}}$ and $T_{\mathrm{gAs}}$, and, observed $T_{\mathrm{g}}$. Though $T_{\mathrm{gAv}}, T_{\mathrm{gAh}}$, and $T_{\mathrm{gAs}}$ differ, $T_{\mathrm{gB}}$ calculated with eqs 12,14 , and 16 , and observed values coincide within $\pm 0.5^{\circ} \mathrm{C}$. If $\delta_{\mathrm{v}}, \delta_{\mathrm{h}}$, or $\delta_{\mathrm{s}}$ is obtained for a composition of a blend, $T_{\mathrm{gB}}$ of other compositions will be estimated by semi-empirical eqs 12,14 , or 16.

\section{Copolymers}

Hirooka et al. reported glass transition temperatures of random and alternating copolymers of poly(methyl acrylate-co-vinyl chloride ) [ $\mathrm{p}$ ( MA-co-VC)], poly ( MA-covinylidene chloride)[p(MA-co-VDC)], poly(methyl methacrylate-co-styrene)[p(MMA-co-St)], and, poly-( $\alpha$-methyl styrene-co-acrylonitrile) $[\mathrm{p}(\alpha \mathrm{MS}-c o-\mathrm{AN})] .{ }^{6} \mathrm{~g}$ in eq 19 is calculated for these random copolymers using $T_{\mathrm{gRD}}$, $T_{\mathrm{gAL}}, T_{\mathrm{g} 1}$, and $T_{\mathrm{g} 2}$. Mean $g$ of these four copolymers is 2.64 for p(MA-ran-VDC), 2.05 for p(MMA-ran-St), 2.68 for $\mathrm{p}(\alpha \mathrm{MS}-$ ran-AN) and 2.56 for $\mathrm{p}(\mathrm{MA}-\mathrm{ran}-\mathrm{VC})$ respectively. These values are between 2 and 3 . If $p=2 x_{1} x_{2}, \delta_{\mathrm{v}}$ and $\delta_{\mathrm{h}}$ of $\mathrm{p}(\mathrm{MA}-$ ran-VDC) and $\mathrm{p}(\mathrm{MA}-\mathrm{ran}-\mathrm{VC})$ are negative, and those of $p$ (MMA-ran-St) and $\mathrm{p}(\alpha \mathrm{MS}-\mathrm{ran}-\mathrm{AN})$ are positive. If $p=3 x_{1} x_{2}$, the signs become reversed.

If $g$ is constant, $T_{\mathrm{gRD}}$ of these random copolymers can be calculated using eq 19. Figure 5 shows the calculated curves of $T_{\mathrm{gRD}} v s$. composition, and observed $T_{\mathrm{g}}$ of $\mathrm{p}(\mathrm{MA}-$ ran-VDC). In Figure 6, the results for $\mathrm{p}$ (MMA-ran-St) and $\mathrm{p}(\alpha \mathrm{MS}-\mathrm{ran}-\mathrm{AN})$ are shown. Since the content of hetero-diad of $\mathrm{p}(\alpha \mathrm{MS}-$ ran-AN $)$ at equi-molar composition is high, ${ }^{6}$ the difference between observed and calculated $T_{\mathrm{g}}$ is slightly large. Except for this point, the calcu- 


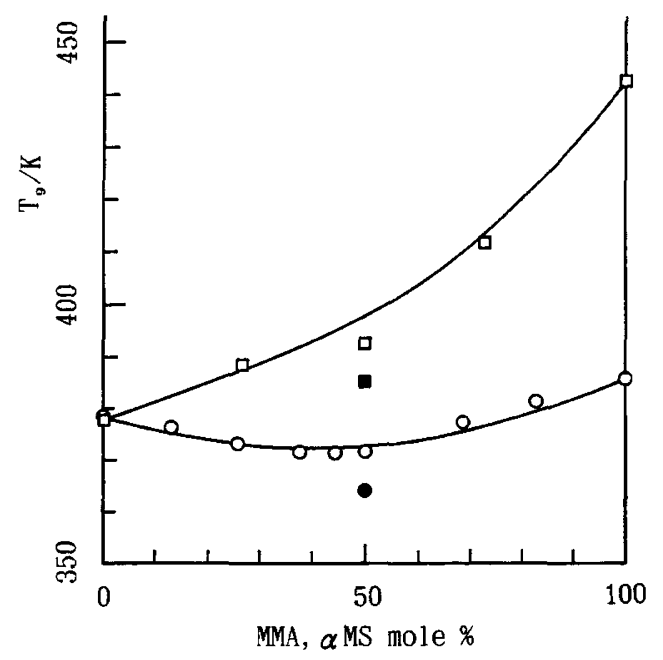

Figure 6. $T_{\text {g }}$ of $\bigcirc$; random copolymers and $\bigcirc$; alternating copolymer of $\mathrm{p}\left(\mathrm{MMA}-\mathrm{co}\right.$-St). $T_{\mathrm{g}}$ of $\square$; random copolymers and $\square$; alternating copolymer of $\mathrm{p}(\alpha \mathrm{MS}-\mathrm{co}-\mathrm{AN})$. Solid lines are calculated with eq 11. $g=2.05$ for $p($ MMA-ran-St) and $g=2.68$ for $p(\alpha$ MSran-AN).

lated curves well reproduce $T_{\mathrm{g}}$ of random copolymers. The average difference between observed and calculated $T_{\mathrm{g}}$ is $0.1^{\circ} \mathrm{C}$, and standard deviation is $1.4^{\circ} \mathrm{C}$. The preci- sion of the data of $T_{\mathrm{g}}$ seems to be insufficient for further discussion. However, from the above results, eq 17 should be useful to describe $T_{\mathrm{g}}$ of copolymers.

Acknowledgments. The author thanks Dr. Hirooka for permitting access to data.

\section{REFERENCES}

1. M. Gordon and J. S. Taylor, J. Appl. Chem., 2, 493 (1952).

2. L. A. Wood, J. Polym. Sci., 28, 318 (1958).

3. P. R. Cauchman, Macromolecules, 11, 1156 (1978).

4. T. K. Kwei, J. Polym. Sci. Lett. Ed., 22, 307 (1984); T. K. Kwei, E. M. Pearce, J. R. Pennacchia, and M. Chatron, Macromolecules, 20, 1174 (1987).

5. M. -J. Brekner, H. A. Schneider, and H. -J. Cantow, Polymer, 29, 78 (1988); H. A. Schneider, Macromol. Chem., 189, 1941 (1988).

6. M. Hirooka and T. Kato, J. Polym. Sci., Lett. Ed., 12, 31 (1974).

7. S. Ichihara, A. Komatsu, and T. Hata, Polym. J., 2, 640 (1971).

8. J. E. McKinney and M. Goldstein, J. Res. Natl. Bur. Std., 78 A, 331 (1974)

9. O. Olabisi and R. Simha, Macromolecules, 8, 206 (1975); S. S. Rogers and L. Mandelkern, J. Phys. Chem., 61, 985 (1957).

10. J. M. O'Reilly and F. E. Karasz, J. Polym. Sci., C, 41, 49 (1966).

11. H. Sasabe and G. T. Moynihan, J. Polym. Sci. Phys. Ed., 16, 1447 (1978). 